\title{
Treatment of Hypertensive Patients with a Fixed-Dose Combination of Bisoprolol and Amlodipine: Results of a Cohort study with More Than 10,000 Patients
}

\author{
Ulrike Hostalek (D) - Danuta Czarnecka $\cdot$ Ernst M. W. Koch
}

To view enhanced content go to www.cardiologytherapy-open.com

Received: July 10, 2015 / Published online: August 8, 2015

(c) The Author(s) 2015. This article is published with open access at Springerlink.com

\section{ABSTRACT}

Introduction: Many patients need more than one antihypertensive agent for effective blood pressure (BP) control. Prescription of a fixed-dose combination (FDC) of bisoprolol and amlodipine in one tablet has been shown to significantly improve patient adherence. This non-interventional study investigated the effects on adherence and BP control of switching from a free-dose combination of the two antihypertensive substances to a FDC in a larger patient population.

Methods: Patients aged $\geq 18$ years with essential hypertension were switched at least 4 weeks prior to study initiation from a

Electronic supplementary material The online version of this article (doi:10.1007/s40119-015-0045-z) contains supplementary material, which is available to authorized users.

U. Hostalek ( $\square)$

Merck KGaA, Darmstadt, Germany

e-mail: ulrike.gottwald-hostalek@merckgroup.com

D. Czarnecka

Jagiellonion University Medical College, Krakow, Poland

E. M. W. Koch

Clinical Research, Alsbach, Germany free-dose combination of bisoprolol and amlodipine to the FDC. Dosage adjustment was implemented only if medically indicated. Adherence was assessed on the basis of the ratio of pills used to pills dispensed (\%) at each visit (pill count). BP and key laboratory values were determined at baseline, 3 and 6 months.

Results: 10,532 patients (average age 59 years; $48 \%$ female) were recruited between 2013 and $2014 ; 22 \%$ of patients had type 2 diabetes and $38 \%$ had cardiovascular disease. The mean doses of the freely combined drugs prior to switching were $5.5 \mathrm{mg}$ bisoprolol and $6.1 \mathrm{mg}$ amlodipine once daily. The mean daily doses prescribed in the FDC were 5.8 and $6.4 \mathrm{mg}$, respectively. Pill counts at 6 months revealed a good to excellent adherence in $>95 \%$ of the patients. Comparison of BP at baseline and at 6 months showed substantial changes (mean systolic BP: 147.3 vs. $130.9 \mathrm{mmHg}$; mean diastolic BP: 87.9 vs. $79.1 \mathrm{mmHg}$ ). Clinically relevant improvement in systolic BP was established for $82 \%$ of patients. In patients with comorbidities, switching to FDC produced a substantial improvement in BP. A total of $89(0.7 \%)$ adverse events (AEs) were reported, including edema, headache, dizziness, 
bradycardia, nausea, and skin reactions. Only three AEs were classified as serious.

Conclusion: These data from a non-interventional study in a large patient population demonstrate the benefits of prescribing a FDC of bisoprolol-amlodipine in terms of an excellent adherence and an associated improvement in control of previously elevated $\mathrm{BP}$, which may be relevant in real-life practice.

Funding: Merck KGaA.

Keywords: Adherence; Amlodipine; Bisoprolol; Blood pressure control; Fixed-dose combination

\section{INTRODUCTION}

For a number of medical research questions, the results produced by the "gold standard" of clinical research-randomized, double-blind, controlled trials (RCTs) of drugs or medical applications-are limited in the evidence they provide regarding potential applications and effects, risks, and patient adherence in a routine medical setting $[1,2]$. Without diminishing the importance and necessity of RCTs in documenting the efficacy and safety of medicinal products, there is a consensus that additional data are required from studies in patients whose diagnosis, treatment, and monitoring exclusively follow normal medical practice [3], while the patients involved benefit from the increased therapeutic freedom versus participation in a RCT.

Carefully planned, conducted, and evaluated non-interventional studies may be particularly useful in drawing conclusions regarding the effects, safety, and-in some cases-acceptance of therapeutic procedures, medicinal products, or medical devices, based on immediate observation of a wide range of individual circumstances and not on findings in a specific selection of clinical trial patients chosen to meet strictly defined criteria. In a non-interventional study, the medical procedures carried out have the sole purpose of providing the best possible care for the individual patient. Non-interventional studies include a varied range of patients with and without comorbidities and do not dictate additional interventions or instructions beyond the treatment concept based on the needs of the patients concerned. Regulatory authorities in many countries now require non-interventional studies-in most cases following the approval of a new drug-and study design guidelines are now available [4].

Systematic analysis of data from RCTs versus non-interventional studies has shown virtually no evidence of superiority of RCTs in terms of assessing the effects of medicinal products [5]. This conclusion applies regardless of the specific design, study population criteria, and data acquisition periods.

Non-interventional studies are conducted in various designs. One such format is a cohort study, in which participants undergo specific medical care and their outcome is monitored and evaluated at certain times $[1,6,7]$. A prerequisite is that the expected effects in real-life conditions are largely similar to those investigated in RCTs and that the investigating sites are qualified to use the investigational material. This helps to minimize the dropout rate. Non-interventional studies of this kind generally involve large sample sizes and may therefore help to identify rare adverse events (AEs).

Event rates in non-interventional studies may also indicate effects and/or risks attributable to certain factors that do not feature in RCTs because of the strict exclusion 
criteria. Non-interventional studies, for instance, enable adherence to a new medication or formulation to be analyzed in real life and correlated with treatment response or other parameters. These data may be important if the success of a prescribed long-term therapy very much depends on adherence with the regimen, e.g., in the treatment of patients with hypertension. Hypertension is one of the most common conditions seen in primary care. Untreated, it is associated with a high risk of myocardial infarction, stroke, renal failure, and premature death $[8,9]$. There is an abundance of evidence showing that blood pressure (BP) should be below $150 / 90 \mathrm{mmHg}$ in patients aged $\geq 60$ years. The corresponding level for younger patients and people with diabetes or renal failure is $140 / 90 \mathrm{mmHg}$ [10].

Clinical trial results show that a very large proportion of patients receiving antihypertensive treatment from primary care physicians do not achieve these recommended BP levels $[11,12]$. Many patients require more than one antihypertensive drug for successful BP control $[13,14]$ in a regimen encompassing different pharmacologic mechanisms of action. A combination of a beta-blocker such as bisoprolol with a calcium channel blocker such as amlodipine is an established option for successful drug treatment of patients with high BP [15]. It is also cited repeatedly in international guidelines [10]. However, prescribing this free-drug treatment regimen presents an adherence challenge for patients, which may considerably jeopardize the desired treatment response [16]. Hence, it seemed justified to develop and investigate a fixed-dose combination (FDC) of the two active substances in all potentially administered dosage regimens (bisoprolol plus amlodipine: $5+5 \mathrm{mg}, 10+5 \mathrm{mg}, 5+10 \mathrm{mg}$,
$10+10 \mathrm{mg})$. These FDCs were tested in various clinical trials [17-19] and produced a significant reduction in previously elevated BP at the respective dose levels employed. The FDCs also achieved better results than regimens based on a free-dose combination of the two agents.

To produce additional evidence for these FDCs, an extensive non-interventional study was conducted involving two chronologically separate periods. The first part of the study was evaluated after 4288 patients had been enrolled and treated for 6 months [20]. Monitoring of the percentage of tablets taken at 6 months revealed a very high rate of good to excellent adherence ( $>95 \%)$. At the same time, a clinically relevant decline in previously elevated BP was noted (systolic 15\%, diastolic $11 \%)$, although most patients had been receiving the same doses of bisoprolol and amlodipine in a free combination.

To further verify the accuracy of these results, the study was continued at the same sites, and a number of new sites were added to include results for around 10,000 patients. This enabled data from the first study period to be checked against the data for the whole of this non-interventional study.

\section{METHODS}

The plan for this non-interventional study proposed individualized antihypertensive treatment in terms of procedures, dosages, follow-up, and final assessment with four different regimens of the active substances bisoprolol and amlodipine in a FDC: $5 \mathrm{mg}$ bisoprolol plus $5 \mathrm{mg}$ amlodipine, $5 \mathrm{mg}$ bisoprolol plus $10 \mathrm{mg}$ amlodipine, $10 \mathrm{mg}$ bisoprolol plus $5 \mathrm{mg}$ amlodipine, and $10 \mathrm{mg}$ bisoprolol plus $10 \mathrm{mg}$ amlodipine. No 
additional measures departing from routine care in this patient population were proposed. Investigating sites were at liberty to choose any necessary medical interventions or additional drugs as they saw fit.

Patients aged $\geq 18$ years with essential hypertension were recruited if they had already been switched from a free combination of bisoprolol 5-10 mg/day and amlodipine $5-10 \mathrm{mg} /$ day to the FDC at least 4 weeks prior to recruitment. Reliable contraception was mandatory in women of childbearing age. Exclusion criteria included pregnancy, lactation, any contraindication to the FDC according to the local label, and any other antihypertensive medication.

The primary endpoint was patient adherence under the FDC measured by tablet count (tablets taken/tablets prescribed $\times 100$ ) and defined as follows: excellent $>90 \%$, good $76-90 \%$, moderate $51-75 \%$, and bad $\leq 50 \%$. BP was measured in a supine position after at least $5 \mathrm{~min}$ rest. All other patient data, clinical findings, and laboratory values were recorded upon availability at study start, after 3 months (voluntary), and after 6 months into case record forms (CRFs). Upon completion of the study, all the entries from the CRFs were transferred to an assessment table (BIAS: Biometric Analysis of Samples, Hanns Ackermann, Frankfurt, Germany).

Access to patient data was restricted exclusively to the investigators. All patients were assigned an ID number before the study to enable anonymous documentation for evaluation purposes. Patients were informed about these data protection measures at the start of the study and asked to sign a consent form to participate in accordance with the conditions described. All procedures followed were in accordance with the ethical standards of the responsible committee on human experimentation (institutional and national) and with the Helsinki Declaration of 1964, as revised in 2013. Informed consent was obtained from all patients for being included in the study.

For data analysis, calculation of means with standard deviations, medians with quartiles and Spearman's correlation analyses, Mantel-Haenszel test for contingency tables, and Cohen's D for effect size were used.

\section{RESULTS}

This multicenter non-interventional study included 10,532 patients who were treated in 68 Polish centers. The demographic data of the patients are summarized in Table 1 . The mean age was 59 years, with a broad range from 19 to 99 years. There was almost no correlation between BP values and patient age. As shown by the median body mass index (BMI), most of the patients were overweight. Dependence of BP values on BMI could not be determined. A large proportion of patients had concomitant cardiovascular diseases $(N=4011,38.1 \%)$ or type 2 diabetes $(N=2313,22 \%)$. Angina pectoris (12.3\%) and arrhythmia (11.1\%) were the most frequent concomitant cardiovascular diseases.

Prior to the switch to the FDC, all patients had been pretreated with a free combination of bisoprolol (mean $5.5 \mathrm{mg}$ once daily) and amlodipine (mean $6.1 \mathrm{mg}$ once daily). The lowest possible dose (5 $\mathrm{mg}$ bisoprolol and $5 \mathrm{mg}$ amlodipine once daily) was prescribed for the majority of patients (75\%); data in Table 1 show that most patients did not reach the target value for systolic BP below $140 \mathrm{mmHg}$. The average dose in the FDC after switching from the free dose was $5.8 \pm 2 \mathrm{mg}$ bisoprolol and $6.4 \pm 3 \mathrm{mg}$ amlodipine once daily. In this respect, the switch to the FDC was only associated with 
Table 1 Demographic data

\begin{tabular}{|c|c|c|c|}
\hline Parameter & & & $N(\%)$ \\
\hline Participants & & & 10,532 \\
\hline Female & & & $5050(47.9)$ \\
\hline Male & & & $5435(52.1)$ \\
\hline Diabetes type 2 & & & $2313(22)$ \\
\hline Cardiovascular comorbidities & & & $4011(38.1)$ \\
\hline Liver disease & & & $157(1.5)$ \\
\hline Kidney damage & & & $347(3.3)$ \\
\hline \multicolumn{4}{|l|}{ Smoking status } \\
\hline Non-smoker & & & $4962(47.1)$ \\
\hline Smoker & & & $2.690(25.5)$ \\
\hline Ex-smoker & & & $2799(26.6)$ \\
\hline No data & & & $81(0.8)$ \\
\hline \multicolumn{4}{|l|}{ Alcohol consumption } \\
\hline None & & & $3779(35.9)$ \\
\hline Not regularly $(0-1 \times$ weekly) & & & $5374(51.1)$ \\
\hline Regularly (2-7× weekly) & & & $1295(12.2)$ \\
\hline No data & & & $84(0.8)$ \\
\hline Parameter & Mean ( $($ SD) & Median & Q1-Q3 \\
\hline Age (years) & $59(11)$ & 59 & $52-67$ \\
\hline Height $(\mathrm{cm})$ & $170.1(17)$ & 170 & $164-177$ \\
\hline Weight $(\mathrm{kg})$ & $81.3(15)$ & 80 & $72-90$ \\
\hline BMI $\left(\mathrm{kg} / \mathrm{m}^{2}\right)$ & $28.1(4)$ & 28 & $25.5-30$ \\
\hline Systolic BP (mmHg) & $147.3(15)$ & 148 & $139-160$ \\
\hline Diastolic BP (mmHg) & $88.6(10)$ & 90 & $80-95$ \\
\hline Pulse (beats/minute) & $76(10)$ & 76 & $68-82$ \\
\hline Fasting glucose $(\mathrm{mg} / \mathrm{dL})(N=2429)$ & $99.1(21)$ & 96 & $88-105$ \\
\hline Duration of hypertension (years & $9.2(5)$ & 7 & $2.5-12$ \\
\hline Duration of free combination treatment prior to switch (months) & $19.5(22)$ & 14 & $7-24$ \\
\hline \multicolumn{4}{|l|}{ Dosages (free combination) (mg/day) } \\
\hline Bisoprolol & $5.5(2)$ & 5 & $5-5$ \\
\hline Amlodipine & $6.1(2)$ & 5 & $5-5$ \\
\hline
\end{tabular}

$B M I$ body mass index, $B P$ blood pressure, $S D$ standard deviation 
minimal dose modification. Thus, when switching from the free to the FDC, no changes in bisoprolol or amlodipine doses were performed in $84 \%$ of patients. A correlation between the amount of the respective doses of bisoprolol and amlodipine on BP values before study entry could not be detected.

At the end of the study (Visit 3 after 6 months), data on patient adherence were available for 8830 (82.2\%) patients (Table 2). Overall, 3710 patients attended Visit 2 after 3 months, as well as Visit 3 after 6 months. Adherence was stable between the second and the third visits; $80.3 \%$ of patients showed an equal share of tablet consumption in both controls. A comparison of the adherence ratings did not show any difference between male and female patients.

The analysis of data for BP control showed a clinically relevant regression of systolic and diastolic values, although no considerable dose changes were made during the study period (Table 3). BP was measured in a supine position after at least $5 \mathrm{~min}$ of rest. Figure 1 shows the proportion of patients with systolic BP changes after 6 months of FDC treatment. It is noteworthy that BP reductions were confirmed for all drug doses tested (Table 4).
Accordingly, remarkable differences can be registered regarding the proportions of patients per quartile between the values at study start and after 6 month if the subdivision of quartiles at study start is maintained (Fig. 2). The reductions in diastolic BP were very similar to the reductions in systolic BP shown in Fig. 2. There was a noticeable correlation between BP values prior to the study and the extent of their decline ( $r$ 0.8).

The importance of adherence for good BP control becomes particularly evident when comparing BP values as a function of patient's behavior. Although only $2 \%$ of patients showed moderate or poor adherence, their BP measurements were remarkably higher than those of patients with good to excellent adherence (Table 5). The benefits of adherence on BP control are confirmed by the improvement in pulse pressure by an average of $58.7 \mathrm{mmHG} \pm 13$ (median 60) at study start versus $51.7 \mathrm{mmHg} \pm 11$ (median 50) after 6 months of treatment. All patients were asked whether they would choose the free combination or the FDC; approximately 97\% of patients preferred the FDC.

Although all patients had been treated with a free-dose combination of bisoprolol and amlodipine and switched to the FDC at least

Table 2 Patient adherence at Visit 3 (after 6 months)

\begin{tabular}{lc}
\hline Adherence $(\%$ of prescribed tablets taken) & $\boldsymbol{N}(\%)$ \\
\hline Excellent $(>90 \%)$ & $7562(85.6)$ \\
Good $(76-90 \%)$ & $1098(12.4)$ \\
Good to excellent $(\geq 76 \%)$ & $8660(98.1)$ \\
Moderate $(51-75 \%)$ & $145(1.7)$ \\
Bad $(<50 \%)$ & $25(0.3)$ \\
Total & $8830(100.0)$ \\
\hline
\end{tabular}


Table 3 BP at study start and after 6 months

\begin{tabular}{|c|c|c|}
\hline & $\begin{array}{l}\text { Systolic BP }(\mathrm{mmHg}) \\
N=9435 \\
\text { Mean }( \pm \text { SD })\end{array}$ & $\begin{array}{l}\text { Diastolic BP }(\mathrm{mmHg}) \\
N=9585 \\
\text { Mean }( \pm \mathrm{SD})\end{array}$ \\
\hline Visit 1 (Study start) & $147.3(15)$ & $87.9(10)$ \\
\hline Visit 3 (after 6 months) & $130.9(10)$ & $79.1(7)$ \\
\hline \multirow[t]{2}{*}{ Difference before-after } & $16.6(16)$ & $9.5(11)$ \\
\hline & $\begin{array}{l}\text { Systolic BP }(\mathrm{mmHg}) \\
N=9435 \\
N(\%)\end{array}$ & $\begin{array}{l}\text { Diastolic BP }(\mathrm{mmHg}) \\
N=9585 \\
N(\%)\end{array}$ \\
\hline Improvement & $7754(82.2)$ & $7010(73.2)$ \\
\hline No change & $884(9.4)$ & $1478(15.4)$ \\
\hline Worsening & $797(8.4)$ & $1097(11.4)$ \\
\hline
\end{tabular}

$B P$ blood pressure, $S D$ standard deviation

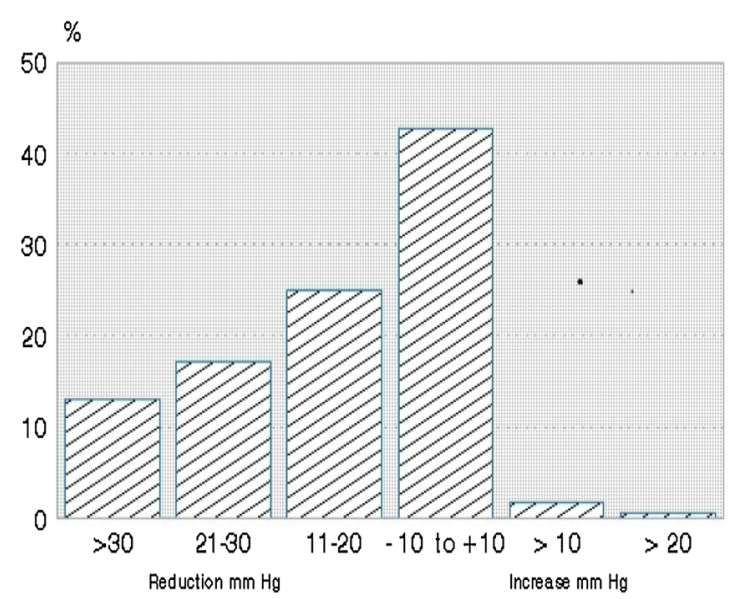

Fig. 1 Changes in systolic blood pressure as 6 months fixed-dose combination treatment. Proportion of patients (\%) showing gradual changes

4 weeks before starting the study, BP measurement at study start showed differences in systolic readings, which were attributable to the respective comorbidities (Table 6). In contrast, patients who reported none of the listed comorbidities had a lower systolic BP (average $145 \pm 10 \mathrm{mmHg}$ ).

After 6 months of treatment with the FDC of bisoprolol and amlodipine with no major dose changes, differences in systolic BP in relation to comorbidities were no longer evident (with diabetes $130.5 \pm 10 \mathrm{mmHg}$, without diabetes $131.9 \pm 10 \mathrm{mmHg}$; with cardiovascular diseases $130.4 \pm 10 \mathrm{mmHg}$, without cardiovascular diseases $131.5 \pm 10 \mathrm{mmHg}$; with renal diseases $130.9 \pm 10 \mathrm{mmHg}$, without renal diseases $131.2 \pm 11 \mathrm{mmHg}$ ).

Another improvement observed during the study was a considerable reduction in heart rate from an average of $75 \pm 10$ to $68.6 \pm 10 \mathrm{bpm}$, which can also help to reduce the health risk for these patients.

\section{Safety Evaluation}

In total, 89 AEs were reported in 70 patients $(0.7 \%)$. The majority of these were edema (41, $46.1 \%)$, headache $(7,7.8 \%)$, dizziness $(6,6.7 \%)$, and bradycardia, nausea, and skin burning/ redness (4, 4.5\% each). Only three AEs (3.4\%) were considered serious, one case of atrial fibrillation (not related), one case of chronic heart failure worsening, and one head injury leading to death (not related). Just nine patients $(0.09 \%)$ discontinued the study due to AEs, including lower limb or ankle swelling or other edema, nausea/malaise, skin burning/redness/ 
Table 4 Changes in systolic and diastolic BP after 6 months based on drug dose

\begin{tabular}{|c|c|c|c|c|}
\hline & \multicolumn{2}{|c|}{ Reduction of systolic BP $\mathrm{mmHg}$} & \multicolumn{2}{|c|}{ Reduction of diastolic BP $\mathrm{mmHg}$} \\
\hline & $\overline{\text { Median }}$ & 1-3 quartiles & Median & 1-3 quartiles \\
\hline Bisoprolol $5 \mathrm{mg}$-amlodipine $5 \mathrm{mg}$ & 15 & $5-25$ & 10 & $0-15$ \\
\hline Bisoprolol $10 \mathrm{mg}$-amlodipine $5 \mathrm{mg}$ & 15 & $6-25$ & 10 & $0-20$ \\
\hline Bisoprolol $5 \mathrm{mg}$-amlodipine $10 \mathrm{mg}$ & 15 & $7-28$ & 10 & $0-20$ \\
\hline Bisoprolol $10 \mathrm{mg}$-amlodipine $10 \mathrm{mg}$ & 20 & $6-30$ & 10 & $0-20$ \\
\hline
\end{tabular}

$B P$ blood pressure

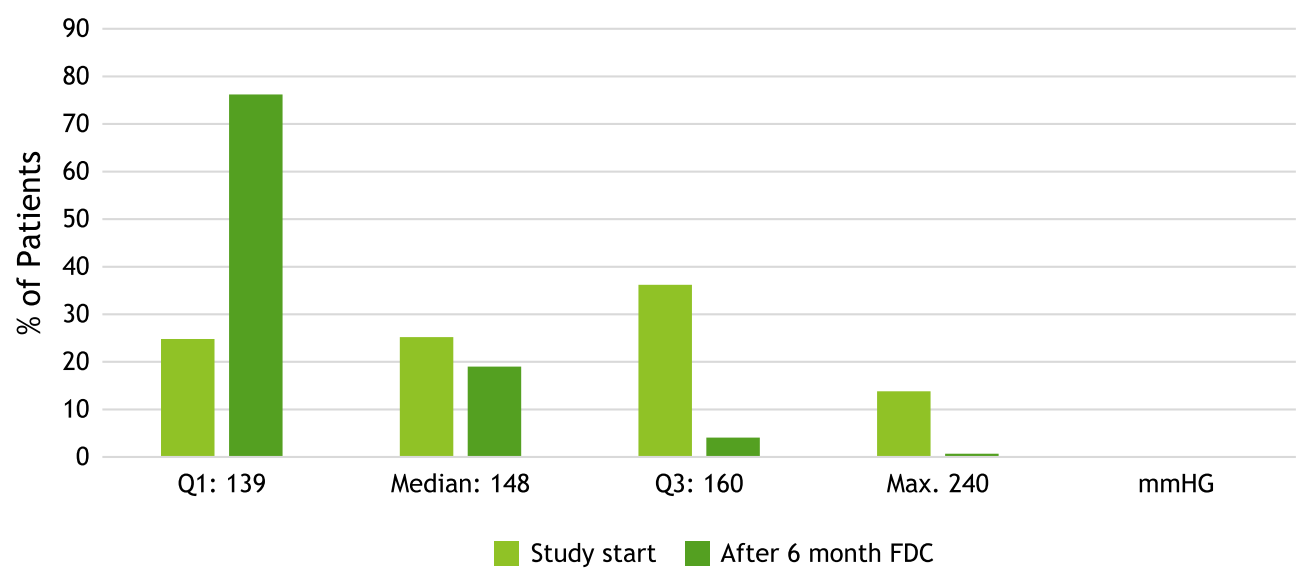

Fig. 2 Comparison of proportion of patients quartiles for systolic blood pressure values. FDC fixed-dose combination

flushing, congestive heart failure worsening/ decompensation, dyspnea, or arrhythmia.

There were only a few laboratory values documented: fasting plasma glucose, HbA1C, serum creatinine, aspartate aminotransferase, and alanine aminotransferase. There were no noticeable changes in these parameters during the study.

\section{DISCUSSION}

Many patients with hypertension have other concomitant conditions, including lipid abnormalities, renal disease, diabetes, cardiovascular events, obesity, and/or smoking. The success of treating hypertension has been limited, and despite well-established approaches to diagnosis and treatment, fewer than half of all hypertensive patients have adequately controlled BP [21].

The most important goal of treatment is to manage hypertension and to deal with the other identified risk factors for cardiovascular disease. For hypertension, the treatment goal for systolic BP is usually $<140 \mathrm{mmHg}$ and for diastolic BP $<90 \mathrm{mmHg}$. Most patients will require more than one drug to efficiently control their BP. The choice of drugs will be influenced by many different aspects and conditions (e.g., diabetes and coronary disease). Generally, there are many clinically proven recommendations for drug selection either for patients whose primary problem is hypertension, or for patients who have a major comorbidity associated with their hypertension. 
Table 5 Correlation of BP after 6 months and adherence

\begin{tabular}{|c|c|c|}
\hline $\begin{array}{l}\text { Adherence } \\
N=8830\end{array}$ & $\begin{array}{l}\text { Systolic BP } \\
(\text { mmHg) } \\
\text { Mean }( \pm \text { SD) } \\
\text { Median } \\
\text { Q1-Q3 }\end{array}$ & $\begin{array}{l}\text { Diastolic BP } \\
\text { (mmHg) } \\
\text { Mean (SD) } \\
\text { Median } \\
\text { Q1-Q3 }\end{array}$ \\
\hline \multirow{2}{*}{$\begin{array}{l}\text { Excellent } \\
(>90 \%)\end{array}$} & $130.5(9)$ & $79.1(7)$ \\
\hline & 130 & 80 \\
\hline$N=7562$ & $125-136$ & $75-83$ \\
\hline Good (76-90\%) & $132.2(11)$ & $79.4(8)$ \\
\hline \multirow[t]{2}{*}{$N=1098$} & 130 & 80 \\
\hline & $125-140$ & $75-85$ \\
\hline \multirow{2}{*}{$\begin{array}{l}\text { Moderate } \\
(51-75 \%)\end{array}$} & $137.1(17)$ & $76.7(10)$ \\
\hline & 140 & 80 \\
\hline$N=145$ & $120-150$ & $70-85$ \\
\hline $\mathrm{Bad}(<50 \%)$ & $144.1(17)$ & $79.8(9)$ \\
\hline \multirow[t]{2}{*}{$N=25$} & 140 & 80 \\
\hline & $127-160$ & $70-88$ \\
\hline
\end{tabular}

$B P$ blood pressure

As regards calcium channel blockers, most experience with these agents has been gained with the dihydropyridines, such as amlodipine and nifedipine, which have shown beneficial effects on cardiovascular and stroke outcomes in hypertension trials [22]. Beta-blockers reduce cardiac output and decrease the release of renin from the kidney. They have strong clinical outcome benefits in patients with histories of myocardial infarction and heart failure and are effective in the management of angina pectoris $[23,24]$.

However, patients find having to take a large number of tablets burdensome [24]. This manifests itself in non-compliance with treatment as directed, or discontinuation of treatment [25]. Failure of hypertensive treatment is demonstrably attributable mainly to poor adherence to treatment on the part of patients [26]. European guidelines for the management of hypertension accordingly recommend treatment with a combination tablet [10] and the results of various studies indicate the clinical relevance of this recommendation $[25,27,28]$.

The study results available to date demonstrate the relationship between successful BP management and patient adherence, in particular since the results from the first study period in more than 4000 patients corresponded fully to those generated in the total population of more than 10,000 patients [20].

The cohort recruited in this study can be considered as representative of real-life hypertension treatment. The study covered a wide range of ages: $23 \%$ of patients were aged $<50$ years and $15 \%$ were aged $>70$ years, thus, most patients were aged between 50 and 70 years. Good to excellent adherence was

Table 6 Dependence on systolic BP values and comorbidities prior to study entry

\begin{tabular}{|c|c|c|c|c|}
\hline \multirow[t]{3}{*}{ Comorbidity } & \multicolumn{2}{|c|}{ Disease present } & \multicolumn{2}{|c|}{ Disease absent } \\
\hline & \multicolumn{2}{|c|}{ Systolic BP (mmHg) } & \multicolumn{2}{|c|}{ Systolic BP (mmHg) } \\
\hline & Mean (士SD) & $\overline{Q 1-m e d i a n-Q 3}$ & Mean (士SD) & $\overline{Q 1-m e d i a n-Q 3}$ \\
\hline Diabetes & $150.7(16)$ & $140-150-160$ & $146.4( \pm 15)$ & $135-145-158$ \\
\hline Cardiovascular diseases & $149.5(16)$ & $140-150-160$ & $145.9( \pm 15)$ & $135-145-160$ \\
\hline Renal diseases & $149.1(17)$ & $140-150-160$ & $147.2(15)$ & $139-147-160$ \\
\hline
\end{tabular}

$B P$ blood pressure 
observed in more than $95 \%$ of patients, and approximately $86 \%$ of prescribed tablets were taken. It can be assumed that the investigators helped to convince patients through intensive discourse and that the consent of patients to take part in this study likewise contributed to this outcome. The consequence is a clinically important decline in previously elevated systolic BP in $82 \%$ of patients, and diastolic BP in $73 \%$ of patients; BP declined overall by 11 percentage points. A therapeutic goal has hence been met that is in line with international guidelines. Regardless of the doses prescribed in each case, similar reductions in BP were achieved. Patients with very high $\mathrm{BP}$ benefitted most from the use of the FDC.

Comparison of results of the preceding study with those of the overall group identified no differences in the changes in $\mathrm{BP}$, which is an indication of rigorous and meticulous project conduct. The results do not contradict those obtained in investigational controlled trials [18, 19]. To that extent, the results of this non-interventional study tend to contradict the commonly postulated study design hierarchy and confirm the insights of other authors on this subject $[29,30]$.

Beyond that, this non-interventional study provides insights into additional factors in the lives of hypertension patients, in particular with regard to their comorbidities and treatment outcomes in these circumstances while receiving routine medical care. The absence of strict inclusion criteria, such as apply in RCTS, enables data to be collected from patients with a variety of comorbidities that may have a meaningful impact on their condition and may constitute additional risks.

The results of this study demonstrate that systematic adherence with treatment instructions contributes to a clinically relevant improvement in BP control in these patients too. The high acceptance of the FDC by the patient was also shown by the fact that $97 \%$ of patients preferred the FDC over the free combination at study end.

Not only BP, but also the pulse pressure and the heart rate as independent risk factors for cardiovascular disease were improved in the study. As far as the safety of treatment is concerned, no AEs or reactions outside the known profile for these active pharmaceutical ingredients occurred during the 6-month period.

The analysis of the study after 6 months was based on the data of 8830 patients, which represented a dropout rate of $17 \%$. Experiences in implementing observational studies show that such a loss of data is quite common and inevitable, and is unlikely to influence the overall result of the study.

When evaluating the data from this study, we paid more attention to clinically relevant results than statistically calculated differences or correlations, because the high number of cases could lead to incorrect conclusions by assessing statistical results only. To that extent, the assessment of the results was more orientated to differences in the confidence intervals and the $C$ values of the effect size taken.

\section{CONCLUSION}

These study results suggest that high adherence rates under a FDC of bisoprolol and amlodipine may lead to better BP control and, thus, to risk reduction for cardiovascular events. The implementation of an observational study with such a high number of patients provides a wide range of information for daily practice and enables us to draw conclusions about the 
relationships between the drug's effect and additional factors.

\section{ACKNOWLEDGMENTS}

This study was carried out as a company-sponsored trial by Merck KGaA. The article processing charges for this publication were funded by Merck KGaA. The authors wish to thank all participating study centers for their dedicated cooperation. The authors also thank Neele Söder, Valentin Lang, and Philippe van der Beck (Alsbach/Bensheim, Germany) for highly reliable and meticulous transfer of data from the case record forms to the analysis file. All named authors meet the International Committee of Medical Journal Editors (ICMJE) criteria for authorship for this manuscript, take responsibility for the integrity of the work as a whole, and have given final approval for the version to be published.

\section{Compliance with Ethical Standards}

Conflict of interest D. Czarnecka was the Principal Investigator and has given lectures for Merck KGaA. U. Hostalek is an employee of Merck KGaA, and E. M. W. Koch is a consultant to the company. All authors had full access to all of the data in this study and take complete responsibility for the integrity of the data and accuracy of the data analysis.

Compliance with ethics guidelines All procedures followed were in accordance with the ethical standards of the responsible committee on human experimentation (institutional and national) and with the Helsinki Declaration of 1964, as revised in 2013. Informed consent was obtained from all patients for being included in the study.
Open Access This article is distributed under the terms of the Creative Commons Attribution-NonCommercial 4.0 International License (http://creativecommons.org/licenses/ by-nc/4.0/), which permits any noncommercial use, distribution, and reproduction in any medium, provided you give appropriate credit to the original author(s) and the source, provide a link to the Creative Commons license, and indicate if changes were made.

\section{REFERENCES}

1. Carlson MD, Morrison RS. Study design, precision, and validity in observational studies. J Palliat Med. 2009;12:77-82.

2. Black N. Why we need observational studies to evaluate the effectiveness of health care. BMJ. 1996;312:1215-8.

3. Diener $H$, Klümper $M$. Neufassung der gemeinsamen Empfehlungen von BfArM und PEI $\mathrm{zu}$ Anwendungsbeobachtungen veröffentlicht. Fachblatt für das gesamte Arzneimittelrecht. 2010;32(9):433-500.

4. Sharp SJ, Poulalilou M, Thompson SG, White IR, Wood AM. A review of published analyses of case-cohort studies and recommendations for future reporting. PLoS One. 2014;9:e101176.

5. Anglemeyer A, Horvath HT, Bero L. Healthcare outcomes assessed with observational study designs compared with those assessed in randomized trials. Cochrane Database Syst Rev. 2014;4:MR000034.

6. Mamdani M, Sykora K, Li P, et al. Readeŕs guide to critical appraisal of cohort studies: 2. Assessing potential for confounding. BMJ. 2005;330:960-2.

7. Rochon PA, Gurwitz JH, Sykora K, et al. Readeŕs guide to critical appraisal of cohort studies: 1 . Role and design. BMJ. 2005;330:895-7.

8. Berry JD, Dyer A, Cai X, et al. Lifetime risks of cardiovascular disease. N Engl J Med. 2012;366: 321-9.

9. Xu W, Goldberg SI, Shubina M, Turchin A. Optimal systolic blood pressure target, time to intensification, and time to follow-up in treatment of hypertension: population based retrospective cohort study. BMJ. 2015;350:h158. 
10. Mancia G, Fagard R, Narkiewicz K, et al. 2013 $\mathrm{ESH} / \mathrm{ESC}$ guidelines for the management of arterial hypertension: the Task Force for the management of arterial hypertension of the European Society of Hypertension (ESH) and of the European Society of Cardiology (ESC). J Hypertens. 2013;31:1281357.

11. Inkster M, Montgomery A, Donnan P, MacDonald T, Sullivan F, Fahey T. Organisational factors in relation to control of blood pressure: an observational study. Br J Gen Pract. 2005;55:931-7.

12. Navar-Boggan AM, Pencina MJ, Williams $K$, Sniderman AD, Peterson ED. Proportion of US adults potentially affected by the 2014 hypertension guideline. JAMA. 2014;311:1424-9.

13. Gradman AH, Basile JN, Carter BL, Bakris GL. American Society of Hypertension Writing Group. Combination therapy in hypertension. J Am Soc Hypertens. 2010;4:42-50.

14. Mancia G, Laurent S, Agabiti-Rosei E, et al. Reappraisal of European guidelines on hypertension management: a European Society of Hypertension Task Force document. J Hypertens. 2009;27:2121-58.

15. Barrios V, Brommer P, Haag U, Calderon A, Escobar C. Olmesartan medoxomil plus amlodipine increases efficacy in patients with moderate-to severe hypertension after monotherapy: a randomized, double-blind, parallel-group, multicentre study. Clin Drug Investig. 2009;29: 427-39.

16. Düsing R. Optimizing blood pressure control through the use of fixed combinations. Vasc Health Risk Manag. 2010;6:321-5.

17. Mehta S, Shah M, Shah A, et al. Efficacy and tolerability of a fixed dose combination of amlodipine and bisoprolol in essential hypertension. Indian Pract. 2005;58:751-9.

18. Rana R, Patil A. Efficacy and safety of bisoprolol plus amlodipine fixed dose combination in essential hypertension. Indian Pract. 2008;61: 225-34.

19. Shiure PA, Tadvi NA, Bajait CS, et al. Comparative effect of fixed dose combination of amlodipine + bisoprolol versus amlodipine and bisoprolol alone on blood pressure in stage-2 essential hypertensive patients. Int $\mathrm{J}$ Med Res Health Sci. 2012;1:13-9.
20. Czarnecka D, Koch EM, Gottwald-Hostalek U. Benefits of a fixed-dose combination of bisoprolol and amlodipine in the treatment of hypertension in daily practice: results of more than 4000 patients. Curr Med Res Opin. 2015;31:875-81.

21. Weber MA, Schiffrin EL, White WB, et al. Clinical practice guidelines for the management of hypertension in the community: a statement by the American Society of Hypertension and the International Society of Hypertension. J Clin Hypertens (Greenwich). 2014;16:14-26.

22. Murdoch D, Heel RC. Amlodipine. A review of its pharmacodynamic and pharmacokinetic properties, and therapeutic use in cardiovascular disease. Drugs. 1991;41:478-505.

23. Davidov ME, Singh SP, Vlachakis ND, et al. Bisoprolol, a once-a-day beta-blocking agent for patients with mild to moderate hypertension. Clin Cardiol. 1994;17:263-8.

24. Bethge $H$, Litterer $G$, Wagner G, Prager G. The 24-hour effect of bisoprolol on blood pressure at rest and during stress. Fortschr Med. 1989;107:153-8.

25. Hagendorff A, Freytag S, Muller A, Klebs S. Pill burden in hypertensive patients treated with single-pill combination therapy-an observational study. Adv Ther. 2013;30:406-19.

26. Monane M, Bohn RL, Gurwitz JH, Glynn RJ, Levin $\mathrm{R}$, Avorn J. The effects of initial drug choice and comorbidity on antihypertensive therapy compliance: results from a population-based study in the elderly. Am J Hypertens. 1997;10:697-704.

27. Jin J, Sklar GE, Min Sen Oh V, Chuen Li S. Factors affecting therapeutic compliance: a review from the patient's perspective. Ther Clin Risk Manag. 2008;4:269-86.

28. Laufs U, Böhm M, Kroemer HK, Schussel K, Griese N, Schulz M. Strategies to improve medication adherence. Dtsch Med Wochenschr. 2011;136: 1616-21.

29. Abel U, Koch A. The role of randomization in clinical studies: myths and beliefs. J Clin Epidemiol. 1999;52:487-97.

30. Concato J. Observational versus experimental studies: whats the evidence for a hierarchy? NeuroRx. 2004;1:341-7. 